7. Kostina A., Zhelnin M., Plekhov O., Panteleev I., Levin L., Semin M. Applicability of Vyalov's equations to ice wall strength estimation // Frattura ed integrita strutturale. - 2020. - V. 14, № 53. - P. 394-405. - DOI: 10.3221/IGF-ESIS.53.30.

8. СП 22.13330.2016. Основания зданий и сооружений. Актуализированная редакция СНиП 2.02.01-83* (с Изменениями № 1, 2, 3). Дата введения 2017-07-01. - Текст электронный // Консорциум КОДЕКС. Электронный фонд правовой и нормативно-технической документации: офиц. сайт. - URL: https://docs.cntd.ru/document/456054206 (Дата обращения 15.04.2021).

9. Zhelnin M., Kostina A., Plekhov O., Panteleev I., Levin L. Numerical analysis of application limits of Vyalov's formula for an ice-soil wall thickness // Frattura ed Integrita Strutturale. - 2019. - V. 13, № 49. P. 156-166. - DOI: 10.3221/IGF-ESIS.49.17.

10. Желнин М.С., Костина А.А., Прохоров А.Е., Плехов О.А., Левин Л.Ю. Численное моделирование искусственного замораживания грунтовых слоев для проходки шахтного ствола. - Текст электронный // XXII Зимняя школа по механике сплошных сред: тез. докл. / ПФИЦ УрО РАН. - Пермь, 2021. - С. 132. - URL: https://conf.icmm.ru/event/2/attachments/2/47/Книга\%20тезисов\%20c\%20обложкой.pdf.

11. Семин М.А., Богомягков А.В., Левин Л.Ю. Теоретический анализ динамики ледопородного ограждения при переходе на пассивный режим замораживания // Записки Горного института. $-2020 .-\mathrm{T}$. 243. - C. 319-328. - DOI: 10.31897/PMI.2020.3.319.

12. Левин Л.Ю., Семин М.А., Зайцев А.В. Контроль и прогноз формирования ледопородного ограждения с использованием оптоволоконных технологий // Стратегия и процессы освоения георесурсов: сб. науч. тр. Вып. 14 / ГИ УрО РАН. - Пермь, 2016. - С. 236-238.

\title{
ПРЕДЛОЖЕНИЯ ПО ИСПОЛЬЗОВАНИЮ АВАРИЙНО-СПАСАТЕЛЬНЫХ СКВАЖИН ДЛЯ ЭВАКУАЦИИ ПЕРСОНАЛА ПРИ АВАРИЙНЫХ СИТУАЦИЯХ В НЕФТЯНЫХ ШАХТАХ
}

\author{
Д.В. Шептунов \\ Горный институт УрО РАН, г. Пермь
}

Аннотация. В статье определена необходимость использования аварийно-спасательных скважин в нефтяных шахтах, приведены результаты анализа норм промышленной безопасности РФ, а также обзор отечественного и мирового опыта эвакуации людей при авариях на шахтах.

Ключевые слова: аварийно-спасательная скважина, система эвакуационного выхода.

\section{Введение}

Одной из основных задач действующих норм промышленной безопасности является сохранение жизни и здоровья работников на опасных производственных объектах (далее ОПО). Не являются исключением и требования к безопасности на предприятиях по добычи тяжелой нефти шахтным способом НШПП «Яреганефть» ООО «ЛУКОЙЛ-Коми».

\section{Требования норм промышленной безопасности}

Главным документом, направленным на обеспечение промышленной безопасности, предупреждение аварий и инцидентов на ОПО нефтегазодобывающих производств, на обеспечение готовности организаций, эксплуатирующих нефтегазодобывающие ОПО, к локализации и ликвидации последствий аварий, является Приказ Ростехнадзора от 15.12.2020 N 534 «Об утверждении федеральных норм и правил в области промышленной безопасности “Правила безопасности в нефтяной и газовой промышленности"» (далее - ФНиП). ФНиП уделяют особое внимание вопросам организации эвакуации персонала шахты как из отдельных выработок, так и с каждого горизонта, а также из шахты в целом на поверхность.

Несмотря на жёсткие требования, предъявляемые к организации процесса эвакуации работников, на шахтах периодически происходят несчастные случаи, связанные не 
только с нарушениями трудовой дисциплины, но и с малым количеством обособленных выходов на дневную поверхность из горных выработок. Имели место аварии, при которых горнорабочие оказывались отрезанными от шахтных стволов и не могли подняться на поверхность. Как показывает практика, при большой протяженности эксплуатируемых горных выработок нефтяных шахт (до 100 км), требований ФНиП о наличии не менее двух выходов на поверхность зачастую оказывается недостаточно.

Дополнительными выходами на поверхность могут стать аварийно-спасательные скважины для эвакуации персонала. На данный момент к подобным скважинам нормативная база не предъявляет каких-либо требований ввиду физического их отсутствия.

\section{Отечественный и мировой опыт}

Наглядным примером необходимости применения аварийно-спасательных скважин является подъём с глубины 200 м на поверхность горнорабочего отрядом ВГСЧ с использованием устройства для спуска и подъёма людей и комплекта альпинистского снаряжения при пожаре, возникшем 24.11.2019 в людском ходке уклонного блока 1-3Д «Север» НШ-1 НШПП «Яреганефть», через воздухоподающую скважину № 107 бис внутренним диаметром 1000 мм. Другой более известной спасательной операцией является эвакуация 33 шахтеров в результате аварии, произошедшей 5 августа 2010 года на шахте Сан-Хосе, через семисотметровую специально пробуренную наклонную аварийно-спасательную скважину диаметром 610 мм [2]. Подъем горнорабочих на поверхность осуществлялся при помощи разработанной и изготовленной на заказ капсулы «Феникс» (рис. 1, 2). Спасательная операция с момента возникновения аварии заняла 69 дней.

Австралийская фирма Safescape предлагает готовую систему оборудования эвакуационных выходов Laddertube, разработанную специально для использования в шахтах (рис. 3, 4). Система состоит из отдельных секций, имеющих замкнутый контур и выполненных из прочного полимера, не подверженного воздействию воды, соли или других минералов. Данная система требует минимального обслуживания и размещается в пределах аварийной скважины диаметром 1,1 м. Подъём персонала на поверхность осуществляется за счет мышечной силы без применения технических устройств.

Также в мировой практике применяются системы эвакуационных выходов, конструкции которых выполнены из оцинкованной стали (см. рис. 5, 6). Такие системы также состоят из отдельных секций, имеющих различную конструкцию, исполнение которой зависит от про-

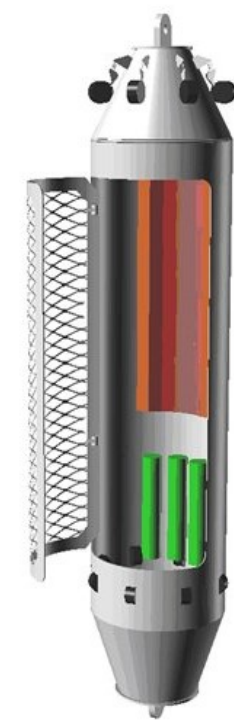

Рис.1. Капсула «Феникс» изводителя. Стоимость данных систем выше, чем изделий из полимера. Подъём персонала на поверхность также осуществляется за счет мышечной силы без применения каких-либо технических устройств.

Наряду с эвакуационными системами лестничного типа, устраиваемыми на всю глубину авариных скважин, рассматривается вариант подъёма персонала с применением технических устройств. К такому варианту относится способ, применяемый при проходке шахтных стволов, когда при аварийного подъема для выдачи людей на поверхность используется металлическая аварийно-спасательная лестница (ЛС-1, ЛС-2) (см. рис. 7), подвешенная на канате к находящейся на поверхности подъемной лебедке с комбинированным (механическим и ручным) приводом. Лестницы состоят из отдельных секций, общая длина лестниц может достигать размеров, приведенных на рисунке 9. Количество секций зависит от расчётного количества персонала [1]. За один цикл можно вывести на поверхность до 30 человек. 


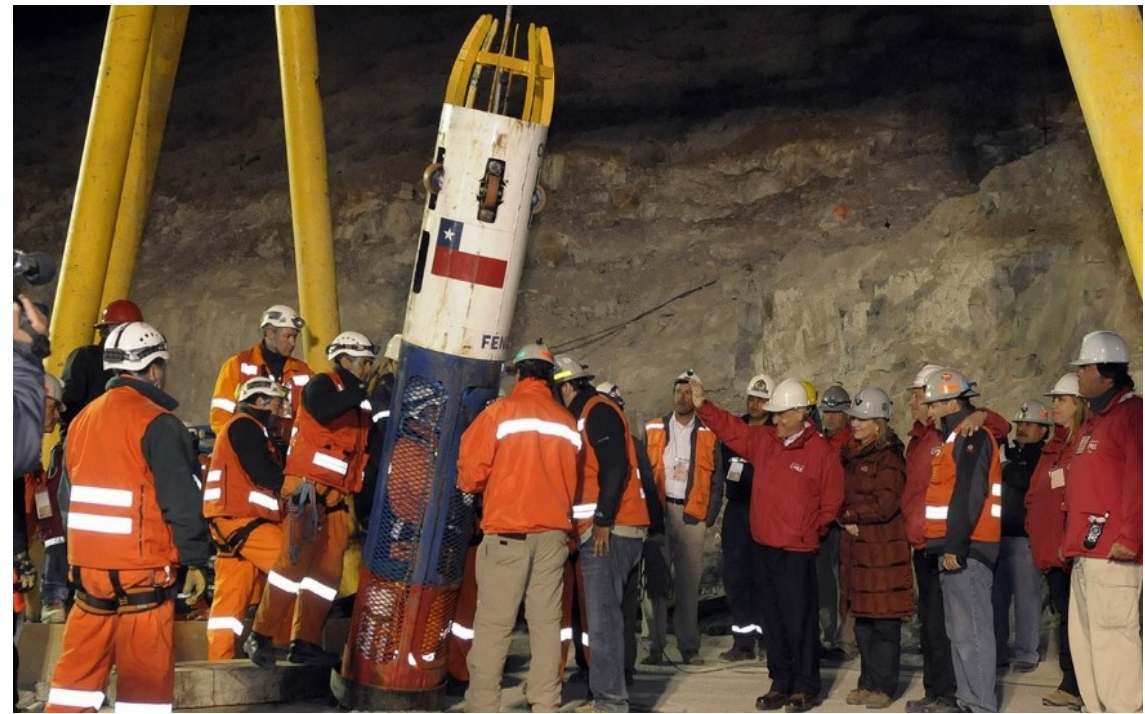

Рис. 2. Подъём горнорабочего на поверхность в капсуле «Феникс»

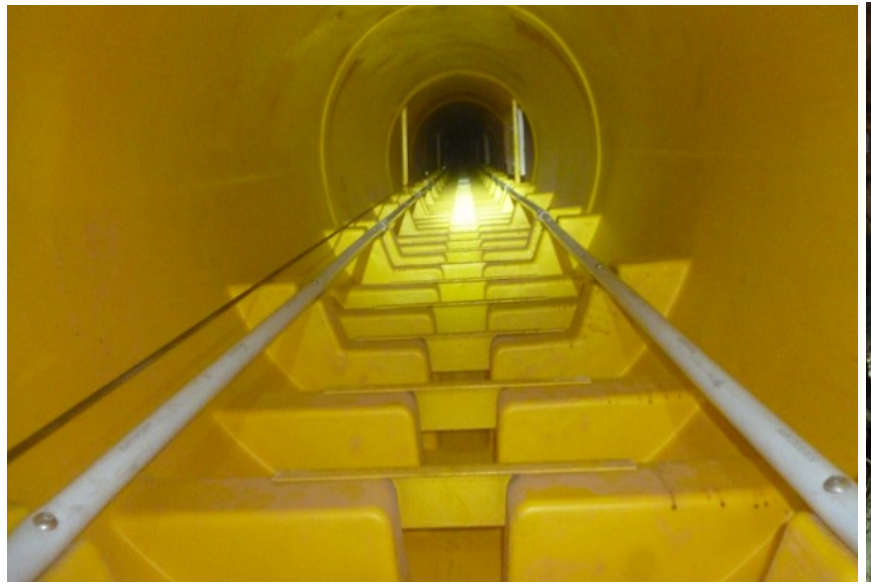

a)

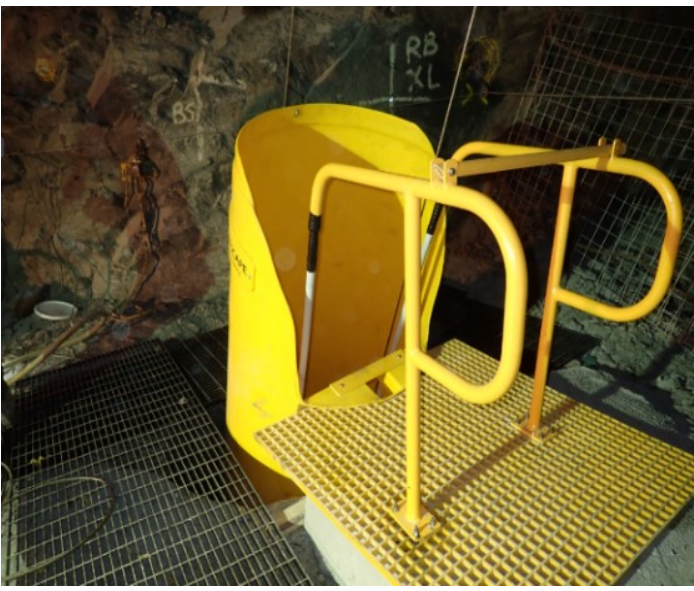

б)

Рис. 3. Система эвакуационных выходов Laddertube: a - вид изнутри; б - устье аварийной скважины с оборудованием

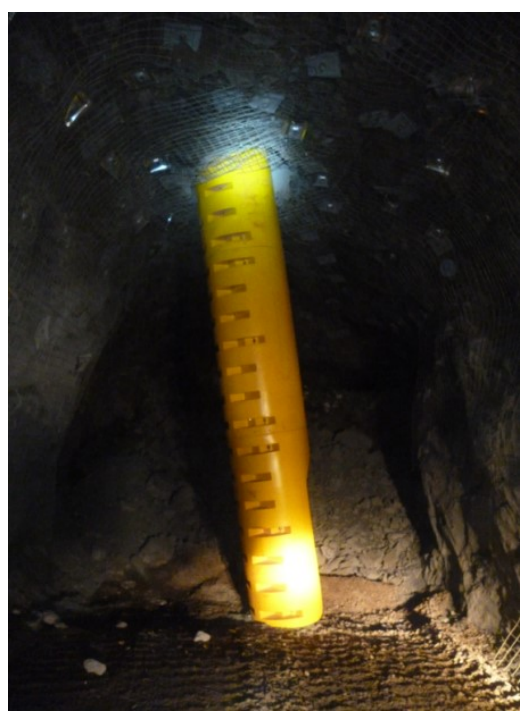

Pис. 4. Laddertube, вид общий 


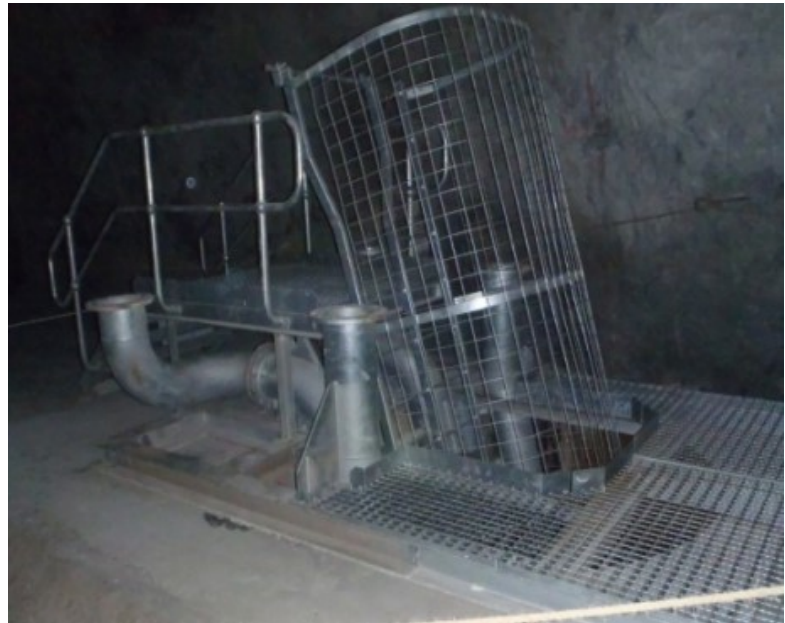

a)

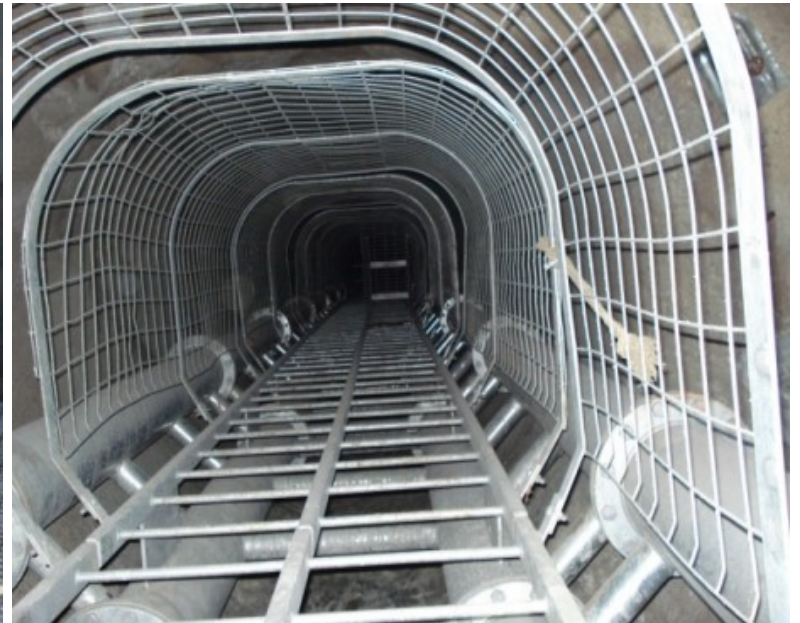

б)

Рис. 5. Система эвакуационных выходов из оцинкованной стали: a - устье аварийной скважины с оборудованием; б - вид изнутри

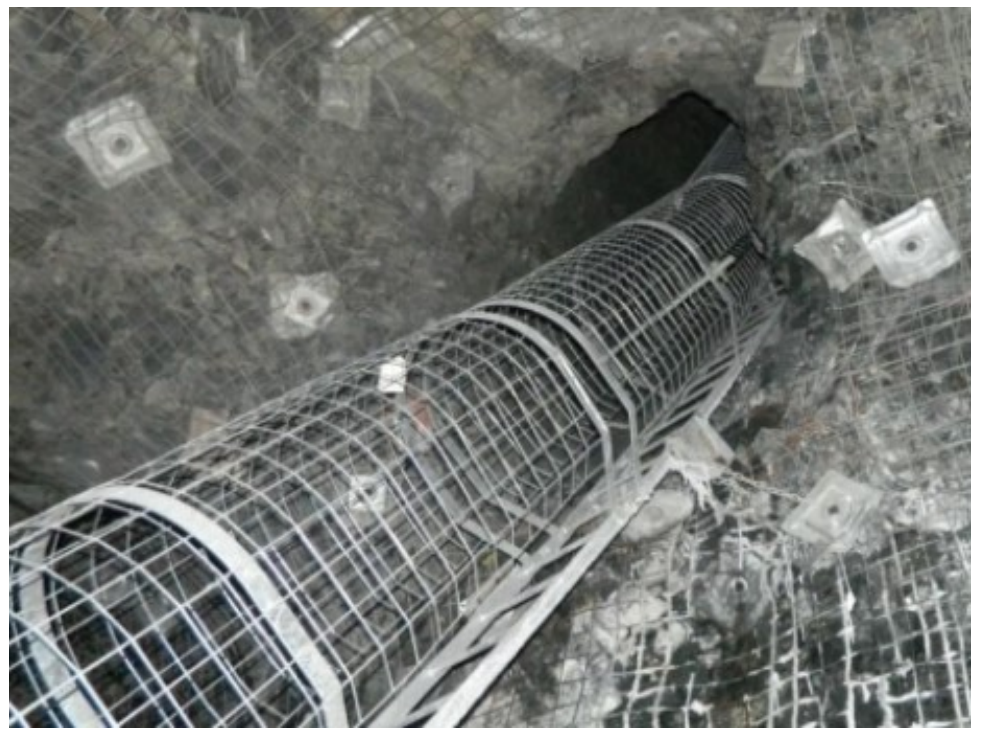

Рис. 6. Вид общий

\section{Классификация}

Аварийными скважинами могут быть не только специально выполненные для этого горные выработки, но и, как было упомянуто ранее, воздухоподающие скважины, а также скважины, применяемые для пропуска инженерных сетей с поверхности в шахту при условии наличия достаточного места для размещения системы эвакуации, т.е. скважины комбинированного назначения.

Исходя из вышеизложенного, можно предложить следующую классификацию аварийных скважин:

1: по расположению в пространстве:

- вертикальные;

- наклонные.

2: по способу подъема персонала:

- с применением технических устройств;

- без применение технических устройств. 
3: по назначению:

- аварийно-спасательные;

- комбинированные.

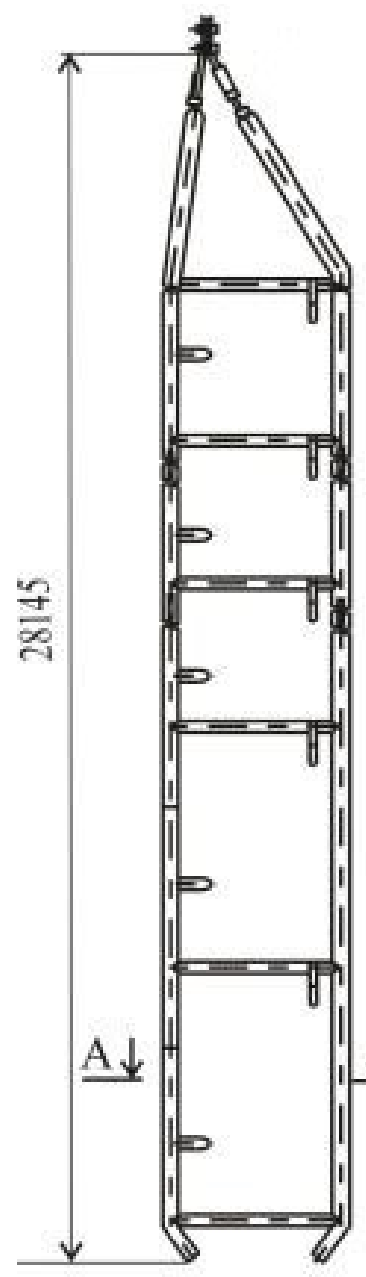

a)

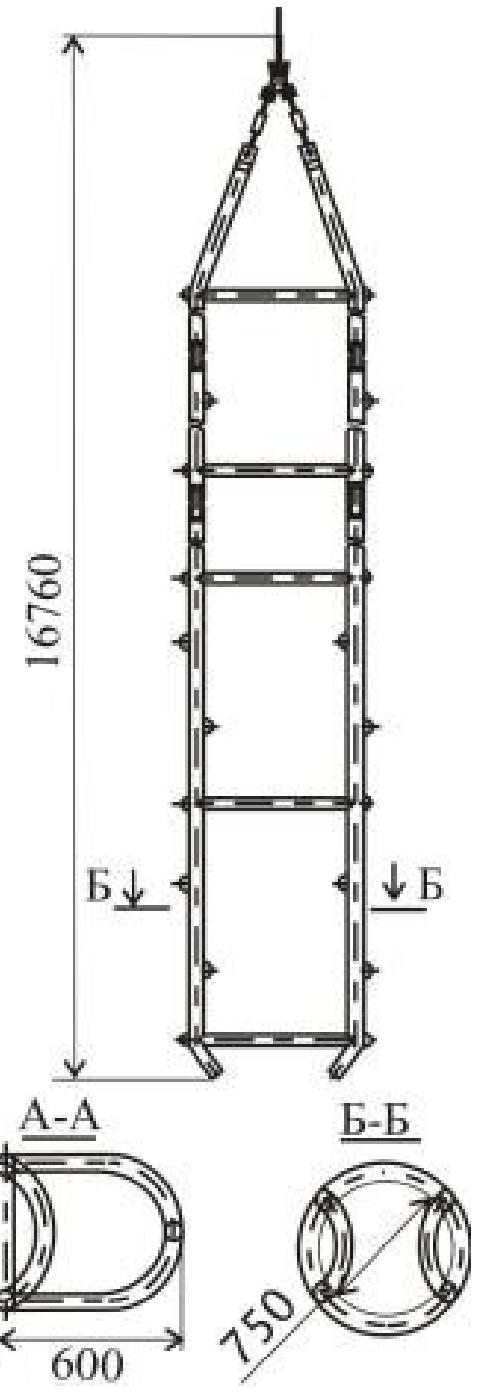

б)

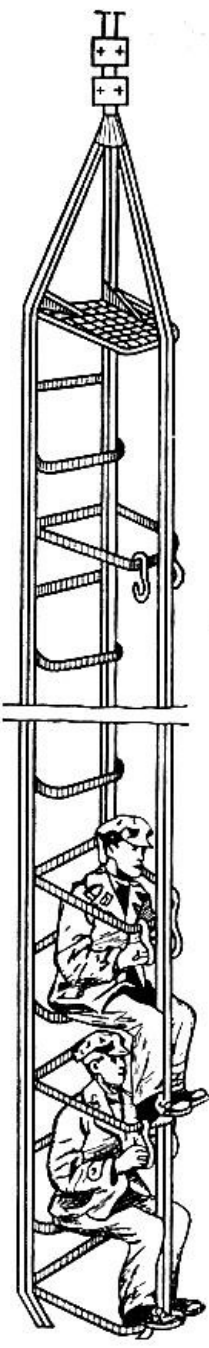

в)

Рис. 7. Спасательные лестницы:

а - ЛС-1; б - ЛС-2; в - схема размещения людей в ЛС-1

\section{Заключение}

При большой протяженности горных выработок нефтешахт и относительно невысокой стоимости в сравнении со строительством шахтных стволов применение комбинированных скважин для осуществления аварийно-спасательных мероприятий является востребованным и оптимальным решением для повышения безопасности персонала при ведении горных и нефтедобычных работ.

\section{БИБЛИОГРАФИЧЕСКИЙ СПИСОК}

1. Строительство стволов шахт и рудников: справ. / под ред. О.С. Докукина, Н.С. Болотских. - М.: Недра, 1991. -516 с.: ил.

2. Пашаев Р. Два месяца в преисподней - // Коммерсанть Власть. - 2010. - № 41, 18 окт. - С. 38-40. 